ISSN 1420-3049

www.mdpi.com/journal/molecules

Review

\title{
Mistaken Identity: Clarification of Rubus coreanus Miquel (Bokbunja)
}

\author{
Jungmin Lee $^{1, *}$, Michael Dossett ${ }^{2}$ and Chad E. Finn ${ }^{3}$
}

1 United States Department of Agriculture (USDA), Agricultural Research Service (ARS), Horticultural Crops Research Unit (HCRU) Worksite, Parma, ID 83660, USA

2 BC Blueberry Council (in partnership with Agriculture and Agri-Food Canada-Pacific Agri-Food Research Centre), 6947 Hwy \#7, P.O. Box 1000, Agassiz, BC V0M 1A0, Canada;

E-Mail: michael.dossett@agr.gc.ca

3 United States Department of Agriculture, Agricultural Research Service, Horticultural Crops Research Unit (HCRU), Corvallis, OR 97330, USA; E-Mail: chad.finn@ars.usda.gov

* Author to whom correspondence should be addressed; E-Mail: jungmin.lee@ars.usda.gov or jlee@uidaho.edu; Tel.: +1-208-722-6701 (ext. 282).

Received: 5 May 2014; in revised form: 3 July 2014 / Accepted: 15 July 2014 /

Published: 18 July 2014

\begin{abstract}
In the U.S., there has been a recent surge in Korean black raspberry products available and in the number of reports about this species appearing in the scientific literature. Despite this, the majority of products sold and the work carried out has been on Rubus occidentalis L., not $R$. coreanus Miquel. The importance of accurate recognition of all starting material is multiplied for research downstream, including genetics/genomics, plant breeding, phenolic identification, food processing improvements and pharmacokinetic investigations. An overview of distinguishing characteristics separating $R$. coreanus from $R$. occidentalis will be presented. Research conducted on correctly identified fruit will also be summarized to aid future studies that might showcase the unique qualities that bokbunja can offer.
\end{abstract}

Keywords: species adulteration; cha tian pao; bramble; caneberry; blackcap 


\section{Introduction}

According to the 1867 records of Friedrich Miquel [1], wild Rubus coreanus Miq. (bokbunja native to eastern Asia) Chinese, Japanese and Korean [2] plants and fruit were collected in Korea by Richard Oldham and verified by Naohiro Naruhashi, as early as 1863 . Within the Rubus genus, $R$. coreanus is in the subgenus, Idaeobatus, along with at least 99 other Rubus species, including other commercially harvested species, such as red raspberry ( $R$. idaeus L.), the Japanese wineberry (R. phoenicolasius L.), the Andean blackberry ( $R$. glaucus Benth.), Mysore raspberry ( $R$. niveus Thunb.) and the black raspberry ( $R$. occidentalis L.) [2]. In the late $1960 \mathrm{~s}$, commercial cultivation of what was thought to be $R$. coreanus (anonymous Korean commercial grower) started in South Korea. While $R$. coreanus (bokbunja) beverage products were marketed as traditional foods, they were unlike a true Korean traditional food (e.g., kimchi) in that they were not readily available in the marketplace until around the year 2004 (personal observation; [3]). A recent literature search showed an increase in $R$. coreanus research articles being published around the year 2007.

Identity concerns over $R$. coreanus plants [3-6] were initially brought to our attention from the fruit images utilized on bokbunja commercial products in the U.S. marketplace; $R$. coreanus (Korean black raspberry) fruit was misrepresented by images of $R$. occidentalis (native to eastern North America, [2]) fruit. Only a small fraction of commercially cultivated black raspberries in Korea are $R$. coreanus, while the majority (reported at $>2,800$ hectares in 2013 cultivated by $>10,000$ farmers; [3,7,8]) are actually $R$. occidentalis (personal observation; anonymous Korean commercial grower; [3-5,8]). Based on randomly amplified polymorphic DNA fragments and chloroplast markers, Eu et al. [3-5] demonstrated that commercially grown black raspberry plants in Korea are more closely related to North American $R$. occidentalis cultivars than to native $R$. coreanus and, in fact, are $R$. occidentalis not $R$. coreanus. Currently, production of $R$. coreanus in Korea is unable to meet the demand for bokbunja products. Identifying the best $R$. coreanus selections or breeding cultivars for commercial plantings is underway by $\mathrm{Kim}$ et al. [8,9], where Kim et al. [9] already has identified promising cultivars (Jungkeum 1, Jungkeum 2, Jungkeum 3, Jungkeum 4 and Jungkeum 5).

Phenolic profiles have become a valuable laboratory tool in small fruit research: our own studies of species, cultivar and genotype in blueberries (Vaccinium corymbosum L., V. deliciosum Piper, $V$. membranaceum Douglas ex Torr., V. ovalifolium Sm. and V. ovatum Pursh.), strawberries (Fragaria spp. L.), elderberries (Sambucus canadensis L. and $S$. nigra L.), black raspberries ( $R$. occidentalis and $R$. coreanus) and lingonberries ( $V$. vitis-idaea L.) were greatly aided by the ability to contrast phenolic profiles [10-21]. This collective phenolic literature directly assists ingredient assurance and product quality control and can be used in authenticity and adulteration monitoring, phenolic degradation, pharmacokinetics, etc., but when misidentified fruit (thought to be that of $R$. coreanus) is harvested, all work downstream becomes misinformation that only causes further disorder. For example, our Rubus phenolic review article [22] was written before access to authenticated $R$. coreanus fruit samples existed [6], and it summarized some scientific papers that were conducted on incorrectly identified $R$. coreanus fruit. The health benefits of $R$. coreanus fruit might be uniquely different from $R$. occidentalis, but this is difficult to gauge based on the current confusion among growers, producers and scientific communities. 
A one-page fact-sheet with photos depicting leaves, flowers, fruit and anthocyanin profiles is available for download to help growers, ingredient suppliers, food processors, and researchers distinguish between these two black raspberries [23]. The objective of this review is to reduce future mistakes by highlighting this issue, to provide a guide to clearly differentiate these species and to provide a summary of phenolic research conducted on the actual $R$. coreanus fruit.

\section{History of Commercialization of Rubus coreanus and $R$. occidentalis Plants}

Rubus occidentalis has been widely grown commercially in eastern North America, where it is native, since the mid-late 1800s [24] and has been used in a variety of food products because of its dark color and unique flavor [22]. While $R$. coreanus is not cultivated commercially in North America, as early as 1937, Darrow [25] recognized its value as a source of resistance to a variety of disease pathogens for breeding. Unfortunately, this potential has not been fully realize; while $R$. coreanus has been valuable in breeding red raspberry [26], hybrids with $R$. occidentalis are highly sterile [27]. It is not clear when $R$. occidentalis was first introduced to Korea. We are unaware of any work comparing the agronomic qualities of these two species as grown in Korea; however, in North America, $R$. coreanus is vigorous and resistant to many of the diseases that cause problems for black and red raspberry growers. Despite this, its fruit tends to be smaller and softer and lack the distinctive flavor of $R$. occidentalis. These reasons, combined with its vigor and thornier canes that may make $R$. coreanus more difficult to manage, could be part of the reason why it is not as commonly grown on a commercial scale.

\section{Morphological and Phenological Differences}

Rubus coreanus flowers are a light to dark purple-pink color [3,6,8,28] compared to the white colored flowers of $R$. occidentalis. Rubus coreanus plants typically have two or more additional leaflets compared to $R$. occidentalis; $R$. coreanus typically has five to nine leaflets that are always pinnately-arranged, while $R$. occidentalis usually has three (ternate) or occasionally five palmately-arranged leaflets (Lee et al. [6]). Rubus coreanus fruit are superficially similar to those of $R$. occidentalis; genotypes of both species produce fruit that ranges from albino (orange), purple to black in color, and the fruit is hollow, as the torus remains on the plant when the fruit is picked [6]. However, well-formed fruit of $R$. occidentalis have smaller drupelets, leading to a smoother surface contour, and usually have some degree of fine white pubescence. This pubescence may occur across the epidermis of the $R$. occidentalis fruit, but is usually concentrated around the edges of the drupelets and is less evident in $R$. coreanus, leading to a somewhat glossier appearance. Fruit of $R$. coreanus can have an unusual bicolored appearance, where anthocyanins concentrate into dark spots on the tip of each drupelet, at the base of the style, against an orange background (see Figure 1c; orange with dark spots on the top of each drupelet of aggregate fruit). Clear images of the leaves, flowers and fruit can be found in Lee et al. [6], Eu et al. [3,4], Kim et al. [9] and in Figure 1. Plant size, vigor, leaf morphology, cane morphology and fruit ripening dates can be found in Lee et al. [6], Keep et al. [28] and Miquel [1]. Rubus coreanus fruit ripen in late July and early August, whereas $R$. occidentalis fruit ripen a few weeks earlier (in June/July) [6,8]. 
Figure 1. There are clear distinguishing morphological differences between Rubus coreanus and $R$. occidentalis. A photo of leaves can be found in Lee et al. [6]. Again, $R$. coreanus has pink flowers (a) and appears glossy, as there is less white hair (pubescence) on the fruit (c). Rubus occidentalis has white flowers (b) and white hair on the fruit (d), which make the fruit appear dull.
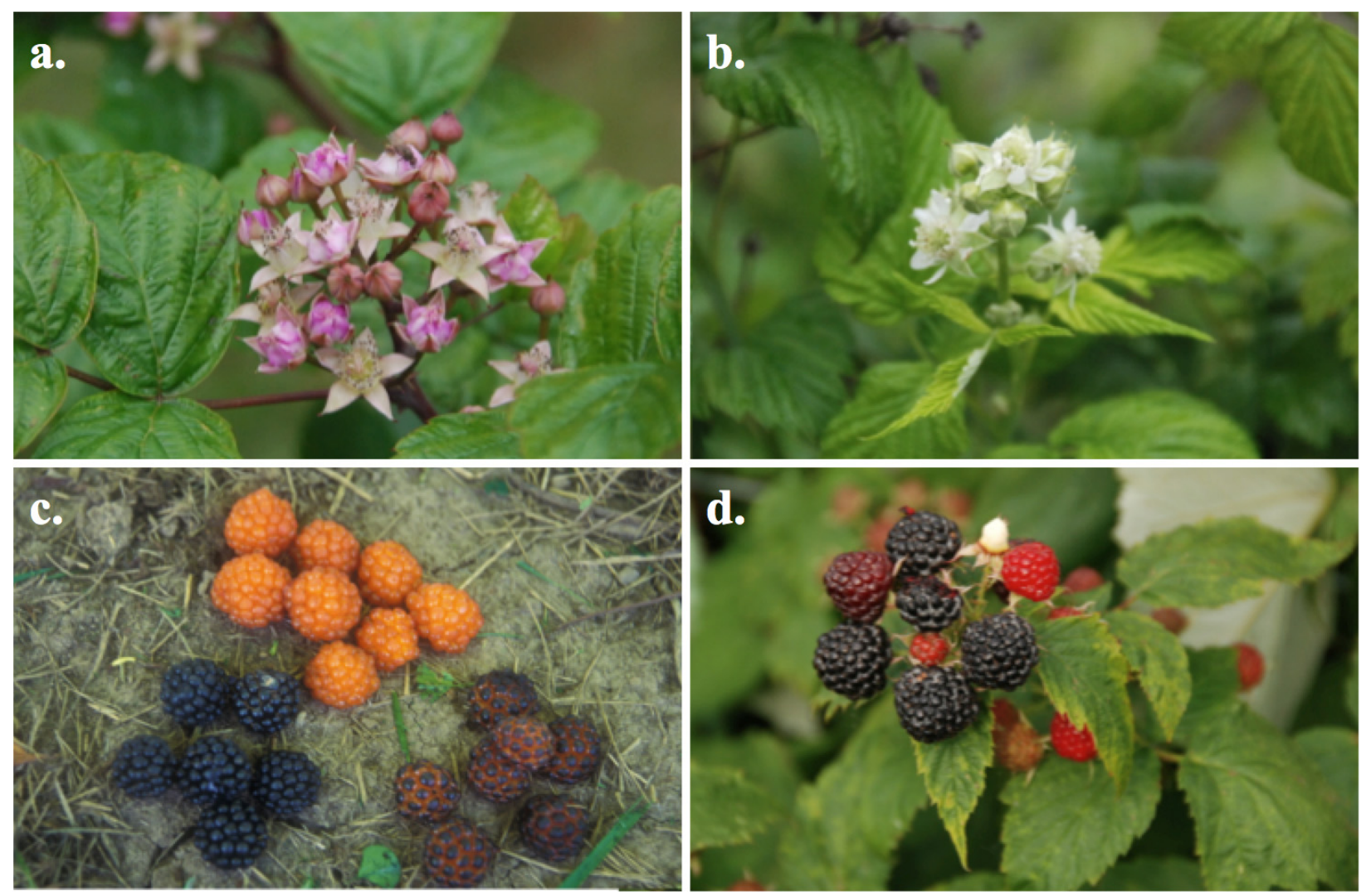

\section{Anthocyanin Profiles}

Besides their unique vegetative traits, the two species have distinctive anthocyanin profiles (Figure 2 and Table 1). Rubus coreanus fruit contains fewer anthocyanins (up to three) compared to R. occidentalis (up to seven) [6,10-12,18-21]. A list of the individual anthocyanins can be found in Table 1. A clear anthocyanin profile of 'Munger' fruit overlaid with $R$. coreanus fruit is shown in Figure 2. In the U.S., the cultivar, Munger ( $R$. occidentalis), is the most widely grown, and 'Munger' fruit has a reliable anthocyanin profile over varying growing seasons (comparing Figure 2 to Dossett et al. [18,19]). While both species contain glycosides of cyanidin and pelargonidin [6,10], trace levels of peonidin-3-rutinoside are only reported in some $R$. occidentalis fruit [18-21].

Our findings [6,10] confirm the identification correctly reported by Kim et al. [29], Heo et al. [30] and Lee et al. [31]. The two anthocyanins Kim et al. [29] found in R. coreanus fruit were glucoside and rutinoside of cyanidin, and cyanidin-3-rutinoside was the main pigment, followed by cyanidin-3-glucoside. In samples from CRUB 1634 16-1 fruit (R. coreanus genotype at USDA-ARS), cyanidin-3-rutinoside (lightest colored fruit) was also the chief anthocyanin, though fruit from two other $R$. coreanus genotypes (CRUB 1634 19-28 and CRUB 1634 19-23) from the same population had more cyanidin-3-glucoside and less cyanidin-3-rutinoside [6]. Heo et al. [30] and Lee et al. [31] also reported only two measurable anthocyanins in $R$. coreanus. Heo et al. [30] described 
cyanidin-3-rutinoside content being greater than cyanidin-3-glucoside in mature fruit, but found the order reversed in immature fruit. Since $R$. coreanus does not contain xylose-containing pigments (i.e., cyanidin-3-xylosylrutinoside and/or cyanidin-3-sambubioside; see Figure 2. and Table 1), their detection indicates the presence of $R$. occidentalis fruit or another unknown contaminant and that the sample is not pure $R$. coreanus.

Figure 2. Anthocyanin profile of Rubus occidentalis cv. Munger (solid line) and $R$. coreanus (dotted line) fruits. Anthocyanin peak identifications in bold are the ones found in $R$. coreanus fruit $[6,10]$.

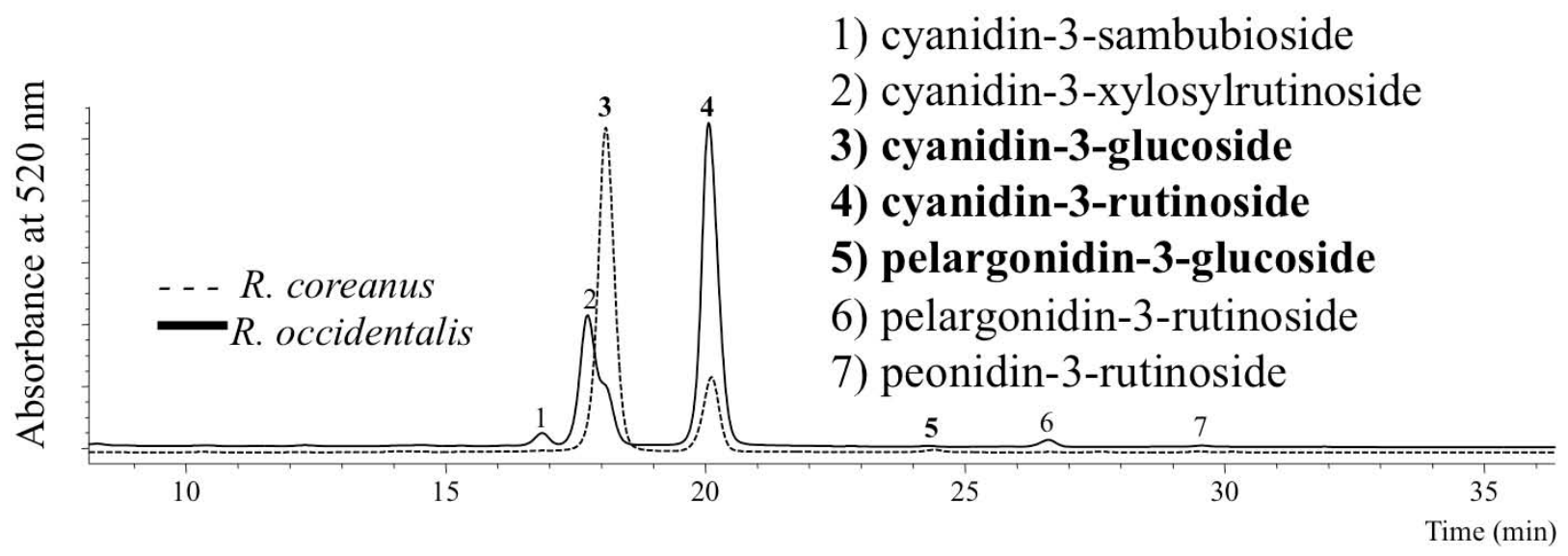

Table 1. Anthocyanins found in Rubus coreanus versus $R$. occidentalis fruit. Anthocyanins listed in the order of HPLC elution. '+' indicates present. '-' indicates not present. ' $+/-$ ' indicates both cases have occurred. A clear recent example of additional anthocyanin profiles of the two species can be found Lee et al. [6], Dossett et al. [18] and Lee [10-12].

\begin{tabular}{cccc}
\hline $\begin{array}{c}\text { Peak Numbering } \\
\text { in Figure 2. }\end{array}$ & Anthocyanin & R. coreanus & R. occidentalis \\
\hline 1 & cyanidin-3-sambubioside & - & + \\
2 & cyanidin-3-xylosylrutinoside & - & $+*$ \\
3 & cyanidin-3-glucoside & + & + \\
4 & cyanidin-3-rutinoside & + & $+/-$ \\
5 & pelargonidin-3-glucoside & $+/-$ & $+/-$ \\
6 & pelargonidin-3-rutinoside & - & $+/-$ \\
7 & peonidin-3-rutinoside & - & +- \\
\hline
\end{tabular}

* Cyanidin-3-xylosylrutinoside was found lacking in the fruit of one wild collected $R$. occidentalis plant out of $>1,000$ genotypes analyzed in our laboratory [6,10-12,18-21]. Lacking cyanidin-3-xylosylrutinoside in R. occidentalis fruit occurs rarely [20].

Due to this difference in the anthocyanin profile (chemotaxonomical distinction), products from these species can be identified in the absence of the vegetative attributes described above. For example, a Korean commercial bokbunja juice sample was obtained, and analysis showed that it had the anthocyanin profile of $R$. occidentalis fruit, not $R$. coreanus fruit [10]. This commercial juice contained cyanidin-3-sambubioside and cyanidin-3-xylosylrutinoside, not found in $R$. coreanus. Researchers should be aware that after processing (i.e., freeze drying, juicing, concentrating, heating), the proportion of the individual anthocyanin peaks might be altered, and unknown polymeric 
anthocyanins may be formed and appear in the chromatograms, as pointed out by Lee et al. [32], Lee and Wrolstad [33], Lee [11], Sadilova et al. [34] and Novotny et al. [35]. Techniques for improved retention of color using food processing methods, ideal storage condition, etc., will result in differing response between $R$. coreanus and $R$. occidentalis, since the predominant cyanidin-based anthocyanins in their fruits have different colors, tinctorial strengths (visual detection threshold), spectral characteristics, thermal degradation kinetics, etc., due to independent structures [34-36]. Different cyanidin-based anthocyanins exhibit altered bioavailability in human subjects [37-39], so the potential health benefits of $R$. coreanus fruit might be unique and different from $R$. occidentalis, as the dominant anthocyanin and the ratio of the individual anthocyanins are characteristic for each species.

\section{Phenolics Other Than Anthocyanins}

From published bokbunja data, two studies that worked with correctly identified $R$. coreanus fruit [30,31] have reported the non-anthocyanin phenolic profile in $R$. coreanus fruit. Phenolic acids (ellagic acid and coumaric acid hexose), flavonol-glycosides (quercetin-glucoside, quercetin-rutinoside, quercetin-glucuronide and kaempferol-glucoside), flavanol polymers (numerous procyanidins; tentatively identified) and hydrolyzable tannins (numerous ellagic acid derivatives; tentatively identified) are in $R$. coreanus fruit [30,31]. It is certain that $R$. coreanus fruit contains ellagic acid derivatives [30,31], since they are widely distributed in Rubus fruit [22], but that group of phenolics remains challenging to identify and quantify [22].

Rubus occidentalis fruit has been reported to contain the same non-anthocyanin phenolic classes as $R$. coreanus, but with some differences in the individual phenolics within: phenolic acids (ellagic acid, ferulic acid, caffeic acid, $p$-coumaric acid, dihydroxybenzoic acid, etc.), flavonol-glycosides (quercetin-glucoside, quercetin-rutinoside, myricetin-glucoside, dihydrokaempferol-glucoside), flavanol monomers (epicatechin) and hydrolyzable tannins (numerous ellagic acid derivatives) [22,39,40].

Phenolics other than anthocyanins in $R$. coreanus and $R$. occidentalis fruits remain a much-needed area of research [22]. Due to the lack of available non-anthocyanin phenolic standards (especially for the larger compounds, like ellagitannins), and the challenges to extract, isolate and analyze these compounds [22], utilizing anthocyanin profiles for authenticity and adulteration is easier and clearer $[11,16,41,42]$. Examples of using anthocyanin for the authenticity of fruit products, cranberry ( $V$. macrocarpon Ait.) juice and $R$. occidentalis fruit sold as dietary supplements are provided in Lee $[11,16]$. Again, randomly amplified polymorphic DNA fragments and other genetic markers can also be used to distinguish these two species, as illustrated by Eu et al. [3,4].

\section{Studies Reporting on the Incorrect Species}

The unique phytochemical composition (specifically anthocyanin), as explained above, is the principal reason why it is crucial that bokbunja processing, storage and pharmacokinetic work be done on the correct species, especially if companies or researchers hope to find that $R$. coreanus fruit and products offer exclusive benefits compared to the more widely available $R$. occidentalis; otherwise, our knowledge of $R$. coreanus fruit benefits will only add to the findings of consuming $R$. occidentalis fruit or potentially create confusing and/or conflicting results. A list of incorrectly identified $R$. coreanus fruit used in further research was summarized before [10], though the three examples below 
emphasize the misunderstandings created from incorrectly identifying the subject species. An interesting note is that Examples 2 and 3 obtained samples from commercial fields and food processors.

(1) Hyun et al. [7] actually reports on the anthocyanin biosynthetic genes involved in $R$. occidentalis, not $R$. coreanus fruit, despite what is reported in the paper. In the fruit image provided by Hyun et al. [7], the pubescence on the aggregate fruit is clearly present, and they report the presence of cyanidin-3-xylosylrutinoside, which is an indicator that these fruits are that of $R$. occidentalis, not $R$. coreanus. This study [7] examined cultivated black raspberry from Gochang, Korea.

(2) $\mathrm{Ku}$ and Mun [43] used black raspberry liquor (cordial) press cake (from commercial liquor processor, Gochang, Korea) for additional phenolic extractions in value-added product development, but the extraction optimizations were conducted on $R$. occidentalis press cakes, not $R$. coreanus, as indicated by the presence of cyanidin-3-sambubioside and cyanidin-3-xylosylrutinoside, which are not found in $R$. coreanus fruit.

(3) Kim et al. [44] used misidentified $R$. coreanus fruit to conduct a phytochemical identification study (reported cyanidin-3-sambubioside presence, which is not found in $R$. coreanus fruit), then used those fruit to conduct a study on whether these (misidentified $R$. coreanus) fruit could aid in reducing DNA damage to cigarette smokers [45]. This study [44] obtained samples from a commercial field from Gokseong, Korea.

\section{Conclusions}

Most cultivated $R$. coreanus fruit in Korea are that of $R$. occidentalis based on vegetative traits, fruit anthocyanin profiles and DNA profiling, as discussed above. Commercial bokbunja product ingredient listings need to be corrected to $R$. occidentalis to prevent further confusion. Since there is nothing wrong with growing $R$. occidentalis in Korea for the functional food market, we only propose that the correct species name is utilized on labeling and documentation to prevent confusion in the marketplace and research community. We are hopeful that future work on Rubus fruit will be clear, whether $R$. coreanus, $R$. occidentalis or a mix of the two is used. It is helpful to have the fruit authenticated by a well-trained plant taxonomist prior to further examining its processing stability, health benefits, etc. Genetic fingerprinting has become a relatively inexpensive service provided by commercial laboratories, and the information produced by $\mathrm{Eu}$ et al. [3,4] would allow any of these laboratories to confirm which species they are using in their study. If a well-trained taxonomist is not available, then this review article and several papers referenced in this work will provide guidance for clear identification.

\section{Acknowledgments}

We thank an anonymous South Korean researcher for their insight into this issue. This project was funded by USDA-ARS CRIS Numbers 5358-21000-047-00D and 5358-21220-002-00D and the Specialty Crop Research Initiative (SCRI) Grant Number 2011-51181-30676 from the USDA-National Institute of Food and Agriculture (NIFA).

Mention of trade names or commercial products in this publication is solely for the purpose of providing specific information and does not imply recommendation or endorsement by the U.S. Department of Agriculture. 


\section{Author Contributions}

Jungmin Lee was lead in compiling research literature and writing of this article with the aid of Michael Dossett and Chad E. Finn.

\section{Conflicts of Interest}

The authors declare no conflict of interest.

\section{References}

1. Miquel, F.A.W. Rubus coreanus Miquel. Ann. Mus. Bot. Lugduno-Batavi. 1867, 3, 34.

2. USDA, ARS, National Genetic Resources Program. Germplasm Resources Information Network-(GRIN) [Online Database]. National Germplasm Resources Laboratory, Beltsville, Maryland, USA. Available online: http://www.ars-grin.gov/cgi-bin/npgs/html/splist.pl?18606 (accessed on 4 February 2014).

3. Eu, G.S.; Chung, B.Y.; Bandopadhyay, R.; Yoo, N.H.; Choi, D.G.; Yun, S.J. Phylogenic relationships of Rubus species revealed by randomly amplified polymorphic DNA markers. J. Crop Sci. Biotech. 2008, 11, 39-44.

4. Eu, G.S.; Park, M.R.; Yun, S.J. Internal transcribed spacer (ITS) regions reveals phylogenic relationships of Rubus species cultivated in Korea. Korean J. Med. Crop Sci. 2009, 17, 165-172.

5. Eu, G.S.; Park, M.R.; Baek, S.H.; Yun, S.J. Phylogenic relationships of Rubus cultivated in Korea revealed by chloroplast DNA spacers. Korean J. Med. Crop Sci. 2010, 18, 266-272.

6. Lee, J.; Dossett, M.; Finn, C.E. Anthocyanin fingerprinting of true bokbunja (Rubus coreanus Miq.) fruit. J. Funct. Foods 2013, 5, 1985-1990.

7. Hyun, T.K.; Lee, S.; Rim, Y.; Kumar, R.; Han, X.; Lee, S.Y.; Lee, C.H.; Kim, J. De-novo RNA sequencing and metabolite profiling to identify genes involved in anthocyanin biosynthesis in Korean black raspberry (Rubus coreanus Miquel). PLoS One 2014, 9, e88292.

8. Kim, S.; Kim, M.; Jang, Y.; Kim, H.; Lee, D. Morphological characteristics and classification of selected population of Rubus coreanus Miq. Life Sci. J. 2013, 10, 144-151.

9. Kim, S.H.; Chung, H.G.; Han, J. Breeding of Korean black raspberry (Rubus coreanus Miq.) for high productivity in Korea. Acta Hort. 2008, 777, 141-146.

10. Lee, J. Establishing a case for improved food phenolic analysis. Food Sci. Nutr. 2014, 2, 1-8.

11. Lee, J. Marketplace analysis demonstrates quality control standards needed for black raspberry dietary supplements. Plant Foods Hum. Nutr. 2014, 69, 161-167.

12. Lee, J.; Dossett, M.; Finn, C.E. Anthocyanin rich black raspberries can be made even better. Acta Hort. 2014, 1017, 127-133.

13. Lee, J.; Finn, C.E. Anthocyanins and other polyphenolics in American elderberry (Sambucus canadensis) and European elderberry (S. nigra) cultivars. J. Sci. Food Agric. 2007, 87, 2665-2675.

14. Lee, J.; Finn, C.E.; Wrolstad, R.E. Comparison of anthocyanin pigment and other phenolic compounds of Vaccinium membranaceum and Vaccinium ovatum native to the Pacific Northwest of North America. J. Agric. Food Chem. 2004, 52, 7039-7044. 
15. Lee, J.; Finn, C.E.; Wrolstad, R.E. Anthocyanin pigment and total phenolics content of three Vaccinium species native to the Pacific Northwest of North America. HortScience 2004, 39, 959-964.

16. Lee, J. Proanthocyanidin A2 purification and quantification of American cranberry (Vaccinium macrocarpon Ait.) products. J. Funct. Foods 2013, 5, 144-153.

17. Finn, C.E.; Moore, P.P.; Yorgey, B.M.; Lee, J.; Strik, B.C.; Kempler, C.; Martin, R.R. 'Charm' strawberry. HortScience 2013, 48, 1184-1188.

18. Dossett, M.; Lee, J.; Finn, C.E. Inheritance of phenological, vegetative, and fruit chemistry traits in black raspberry. J. Am. Soc. Hort. Sci. 2008, 133, 408-417.

19. Dossett, M.; Lee, J.; Finn, C.E. Variation of anthocyanins and total phenolics in black raspberry populations. J. Funct. Foods 2010, 2, 292-297.

20. Dossett, M.; Lee, J.; Finn, C.E. Characterization of a novel anthocyanin profile in wild black raspberry mutants: An opportunity for studying the genetic control of pigment and color. J. Funct. Foods 2011, 3, 207-214.

21. Dossett, M.; Lee, J.; Finn, C.E. Anthocyanin content of wild black raspberry germplasm. Acta Hort. 2012, 946, 43-47.

22. Lee, J.; Dossett, M.; Finn, C.E. Rubus fruit phenolic research: The good, the bad, and the confusing. Food Chem. 2012, 130, 785-796.

23. Developing the Genomic Infrastructure for Black Raspberries. Available online: http://blackraspberries.com (accessed on 17 July 2014).

24. Jennings, D.L. Raspberries and Blackberries: Their Breeding, Diseases and Growth; Academic Press: San Diego, CA, USA, 1988.

25. Darrow, G.M. Blackberry and raspberry improvement. In Yearbook of The United States Department of Agricultur; U.S. Government Printing Office: Washington, DC, USA, 1937; pp. 496-553.

26. Keep, E.; Knight, W.H.; Parker, J.H. Rubus coreanus as donor of resistance to cane disease and mildew in red raspberry breeding. Euphytica 1977, 26, 505-510.

27. Williams, C.F. Influence of parentage in species hybridization of raspberries. J. Amer. Soc. Hort. Sci. 1950, 56, 149-156.

28. Keep, E.; Knight, W.H.; Parker, J.H. The inheritance of flower colour and vegetative characters in Rubus coreanus. Euphytica 1977, 26, 185-192.

29. Kim, S.J.; Lee, H.J.; Kim, B.S.; Lee, D.; Lee, S.J.; Yoo, S.H.; Chang, H.I. Antiulcer activity of anthocyanins from Rubus coreanus via association with regulation of the activity of matrix metalloproteinase-2. J. Agric. Food Chem. 2011, 59, 11786-11793.

30. Heo, S.; Lee, D.Y.; Choi, H.K.; Lee, J.; Kim, J.H.; Cho, S.M.; Lee, H.J.; Auh, J.H. Metabolite fingerprinting of bokbunja (Rubus coreanus Miquel) by UPLC-qTOF-MS. Food Sci. Biotech. 2011, 20, 567-570.

31. Lee, D.Y.; Heo, S.; Kim, S.G.; Choi, H.K.; Lee, H.J.; Cho, S.M.; Auh, J.H. Metabolomic characterization of the region- and maturity-specificity of Rubus coreanus Miquel (bokbunja). Food Res. Int. 2013, 54, 508-515.

32. Lee, J.; Durst, R.W.; Wrolstad, R.E. Impact of juice processing on blueberry anthocyanins and polyphenolics: Comparison of two pretreatments. J. Food Sci. 2002, 67, 1660-1667. 
33. Lee, J.; Wrolstad, R.E. Extraction of anthocyanins and polyphenolics from blueberry processing waste. J. Food Sci. 2004, 69, C564-C573.

34. Sadilova, E.; Stintzing, F.C.; Carle, R. Thermal degradation of acylated and nonacylated anthocyanins. J. Food Sci. 2006, 71, C504-C512.

35. Novotny, J.A.; Clevidence, B.A.; Kurilich, A.C. Anthocyanin kinetics are dependent on anthocyanin structure. Br. J. Nutr. 2012, 107, 504-509.

36. Stintzing, F.C.; Stintzing, A.S.; Carle, R.; Frei, B.; Wrolstad, R.E. Color and antioxidant properties of cyanidin-based anthocyanin pigments. J. Agric. Food Chem. 2002, 50, 6172-6181.

37. Aura, A.; Martin-Lopez, P.; O’Leary, K.A.; Williamson, G.; Oksman-Caldentey, K.M.; Poutanen, K.; Santos-Buelga, C. In vitro metabolism of anthocyanins by human gut microflora. Eur. J. Nutr. 2005, 44, 133-142.

38. Charron, C.S.; Kurilich, A.C.; Clevidence, B.A.; Simon, P.W.; Harrison, D.J.; Britz, S.J.; Baer, D.J.; Novotny, J.A. Bioavailability of anthocyanins from purple carrot juice: Effects of acylation and plant matrix. J. Agric. Food Chem. 2009, 57, 1226-1230.

39. Stoner, G.D. Food stuffs for prevention cancer: The preclinical and clinical development of berries. Cancer Prev. Res. 2009, 2, 87-194.

40. Paudel, L.; Wyzgoski, F.J.; Scheerens, J.C.; Chanon, A.M.; Reese, R.N.; Smiljanic, D.; Wesdemiotis, C.; Blakeslee, J.J.; Riedl, K.M.; Rinaldi, P.L. Nonanthocyanin secondary metabolites of black raspberry (Rubus occidentalis L.) fruits: Identification by HPLC-DAD, NMR, HPLC-ESI-MS, and ESI-MS/MS analyses. J. Agric. Food Chem. 2013, 61, 12032-12043.

41. Hong, V.; Wrolstad, R.E. Detection of adulteration in commercial cranberry juice drinks and concentrates. J. Aoac. Int. 1986, 69, 208-213.

42. Penman, K.G.; Halstead, C.W.; Matthias, A.; de Voss, J.J.; Stuthe, J.M.; Bone, K.M.; Lehmann, R.P. Bilberry adulteration using the food dye amaranth. J. Agric. Food Chem. 2006, 54, 7378-7382.

43. $\mathrm{Ku}, \mathrm{C} . \mathrm{S}$; Mun, S.P. Optimization of the extraction of anthocyanin from bokbunja (Rubus coreanus Miq.) marc produced during traditional wine processing and characterization of extracts. Bioresour. Technol. 2008, 99, 8325-8330.

44. Kim, H.S.; Park, S.J.; Hyun, S.H.; Yang, S.O.; Lee, J.; Auh, J.H.; Kim, J.H.; Cho, S.M.; Marriott, P.J.; Choi, H.K. Biochemical monitoring of black raspberry (Rubus coreanus Miquel) fruits according to maturation stage by ${ }^{1} \mathrm{H}-\mathrm{NMR}$ using multiple solvent systems. Food Res. Int. 2011, 44, 197-1987.

45. Suh, H.W.; Kim, S.H.; Park, S.J.; Hyun, S.H.; Lee, S.K.; Auh, J.H.; Lee, H.J.; Cho, S.M.; Kim, J.H.; Choi, H.K. Effect of Korean black raspberry (Rubus coreanus Miquel) fruit administration on DNA damage levels in smokers and screening biomarker investigation using ${ }^{1} \mathrm{H}-\mathrm{NMR}$-based metabolic profiling. Food Res. Int. 2013, 54, 1255-1262.

(C) 2014 by the authors; licensee MDPI, Basel, Switzerland. This article is an open access article distributed under the terms and conditions of the Creative Commons Attribution license (http://creativecommons.org/licenses/by/3.0/). 